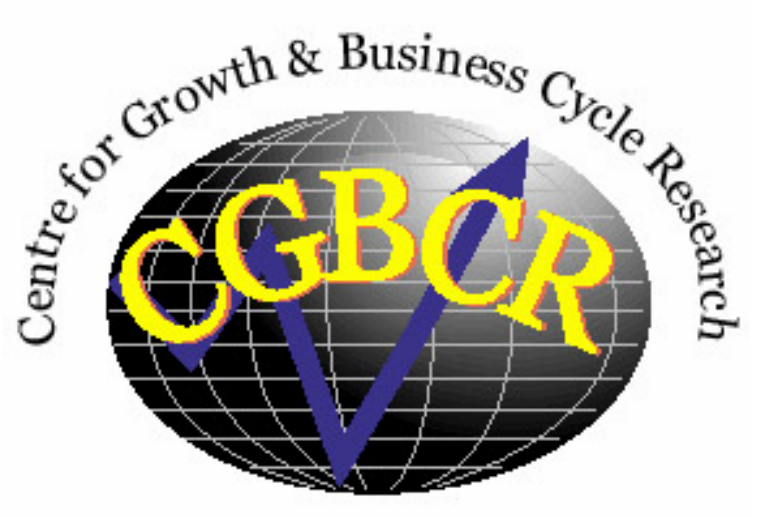

Discussion Paper Series

\title{
Business Cycle Synchronization of the Euro Area with the New and Negotiating Member Countries \\ By
}

Christos S. Savva, Kyriakos C. Neanidis and Denise R. Osborn

Centre for Growth and Business Cycle Research, Economic Studies, University of Manchester, Manchester, M13 9PL, UK

October 2007

Number 091

Download paper from:

http://www.socialsciences.manchester.ac.uk/cgbcr/discussionpape rs/index.html 


\title{
Business Cycle Synchronization of the Euro Area with the New and Negotiating Member Countries*
}

\author{
Christos S. Savva ${ }^{a}$ \\ Kyriakos C. Neanidis ${ }^{b}$ \\ Denise R. Osborn ${ }^{\text {b }}$

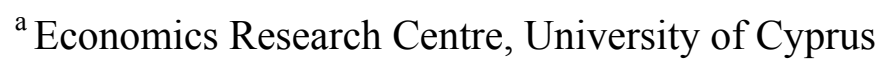 \\ ${ }^{\mathrm{b}}$ Centre for Growth and Business Cycle Research, Economics, \\ University of Manchester
}

October 23, 2007

\begin{abstract}
We examine business cycle synchronizations between the euro area and the recently acceded EU and currently negotiating countries. Strong evidence is uncovered of time-variation in the degree of comovement between the cyclical components of monthly industrial production indicators for each of these countries with a euro area aggregate, which is then modeled through a bivariate VAR-GARCH specification with a smoothly time-varying correlation that allows for structural change. Where required to account for the observed time-variation in correlations, a double smooth transition conditional correlation model is used to capture a second structural change event. After allowing for dynamics, we find that all new EU members and negotiating countries have at least doubled their business cycle synchronization with the euro area, or changed from negative to positive correlations, since the early 1990s. Furthermore, some have exhibited $U$-curved or hump-shaped business cycle correlation patterns. The results point to great variety in timing and speed of the correlation shifts across the country sample.
\end{abstract}

JEL Classifications: C22; E32;

Keywords: Business Cycles, Conditional Correlations, Synchronization, Volatility.

\footnotetext{
* Acknowledgements: We would like to thank the participants of the Fourth Conference on Growth and Business Cycles in Theory and Practice 2007 hosted by the CGBCR, University of Manchester for comments on an earlier draft of the paper. We are particularly grateful to Annastiina Silvennoinen for sharing with us her code for the DSTCC-GARCH model and the corresponding LM test.
} 


\section{Introduction}

On $1^{\text {st }}$ of May 2004, 10 countries (Czech Republic, Estonia, Cyprus, Latvia, Lithuania, Hungary, Malta, Poland, Slovenia, and Slovakia) became members of the European Union (EU). In addition, two other countries (Bulgaria and Romania) joined the Union on $1^{\text {st }}$ of January 2007, while three more countries (Croatia, Turkey, and FYROM) are at various stages of negotiation for membership. Once the new members and candidate countries meet the Maastricht convergence criteria, they will also join the euro area (or European Monetary Union, EMU), implying that their monetary policy will be determined by the European Central Bank (ECB). ${ }^{1}$

Joining the EMU mandates a stabilization cost for each country since they lose the control of their exchange rate and the independence of their monetary policy. As shown by the New Keynesian monetary policy models of Rogoff (1985) and Clarida et al. (1999), among others, the ECB will respond more successfully to aggregate shocks and implement its policy with greater ease, if euro area members have less volatile and more synchronized business cycles. In particular, theory predicts that the more synchronized the business cycles among the member states, the lower the probability of asymmetric shocks, and thus the less painful the loss of independent monetary policy. This implies that business cycle convergence represents a key characteristic for the success of the common monetary policy in Europe.

Intuitively, if the business cycle of a country is very highly correlated with the EMU-wide cyclical output, then monetary policy conducted by the ECB will be a very close substitute for the country's independent monetary policy. On the other hand, non-synchronization of cycles may yield a situation where ECB monetary policy amplifies the country's business cycle, thus aggravating the macroeconomic cost of EMU membership.

There is an extensive literature on business cycle synchronization in Europe that can be largely divided into two categories. The first category examines the co-movements of cycles of European countries with each other and/or with the US. For instance, Artis (2003) uses the HodrickPrescott (HP) filter to obtain the cyclical component of quarterly GDP series in 23 countries, of which 15 are European. He finds that during 1970-2001 whilst some European nations seem to exhibit high correlation with each other and with the US (Germany, Austria, Switzerland, and the Netherlands), another European group (France, Spain, Belgium, Italy, and Denmark) is highly correlated with Japan, and that there are other countries that show no tendency of

\footnotetext{
${ }^{1}$ From the new members, Slovenia has joined EMU on the $1^{\text {st }}$ of January 2007, while Cyprus and Malta will join in January 2008.
} 
synchronization (Ireland, Finland, Sweden, Portugal, the UK, and Norway). Angeloni and Debola (1999) limit their analysis to that between German and other European business cycles and recover fluctuations in industrial production indices, which show increasing correlations during 1993-1997. More recently, Koopman and Azevedo (2007) with the use of a technique that allows for time-varying association patterns in different cycles illustrate that French and German GDP fluctuations display a high degree of association with the euro area over 1970-2001, while the Spanish and Italian cycles became more synchronized only after 1980.

The second category of studies focuses on the degree of business cycle synchronization between the euro area and the new members of the EU and its candidate countries. In this context, Korhonen (2003) examines monthly indicators of industrial production in the euro area and nine central east-European countries (CEECs). He finds that some CEECs, especially Hungary, exhibit a high correlation with the euro-area business cycle. Correlation seems to be at least as high as in some smaller EMU members (e.g., Portugal and Greece). Fidrmuc (2004) also finds that the business cycle for Hungary, Slovenia, and (to a lesser extent) Poland correlates strongly with the German cycle.

In a similar way, Artis et al. (2004) compute business cycles as deviations from the HP band-pass cycles and find that Hungarian and Polish business cycles are the most similar to the euro area cycle. Furthermore, Darvas and Szapáry (2005) examine the synchronization of business cycles between new and old EU members with Hungary, Poland, and Slovenia and show strong improvement in cyclical correlations as moving from 1993-1997 to 1998-2002. In general these results seem to support the findings of Kočenda (2001) and Kutan and Yigit (2004), who report increasing convergence between the CEECs and the EU.

More recently, however, Furceri and Karras (2006) identify countries (such as Slovenia, Cyprus, and Hungary) whose business cycle is already well synchronized with the EMU, compared to countries (such as Latvia and Estonia) that exhibit low synchronization, and countries (such as Romania, Turkey and Croatia) with systematically negative correlations.

All these studies share the following feature: they consider a uniform correlation coefficient for the entire period under investigation, or, in the best case, they exogenously determine time period sub-samples for which the potential change in the correlation is assessed. For the latter, this means that the empirical tests for changes in correlations among business cycles involve some 
sort of two step approach, where in the first step correlations are calculated over either fixed or moving sub-samples, and in the second step the presence of level shifts or trends is assessed.

However, neither of the two methods is appropriate in establishing the magnitude of the business cycles synchronization when this may change over time. The estimation of a uniform (constant) correlation coefficient fails to consider potential regime switches, while the two step tests may suffer from statistical deficiencies. Boyer et al. (1999) show that changes in correlations over time or across regimes cannot be detected reliably by splitting a sample according to the realized values of the data, essentially because statistical inference based on ex-post sample splitting is not valid when conducted as if the date of change was known a priori. ${ }^{2}$ As they argue, it is not possible to assess the presence of an upward trend in correlations by looking at the (trending) behavior of sub-sample estimates of correlations. Therefore, tests of changes in correlations are often severely biased.

In our analysis, we take into account such considerations when examining the business cycles synchronization of the euro area with the new members of the EU and its negotiating countries, with the use of monthly industrial production data over the period January 1980 (or the earliest date available) to June 2006. Our setup employs a bivariate VAR-GARCH specification that models the conditional volatility of the business cycle and allows for a single smooth transition in the correlation specification (STCC-GARCH) adopted by Berben and Jansen (2005) and Silvennoinen and Teräsvirta (2005) and a double smooth transition specification (DSTCCGARCH) recently proposed by Silvennoinen and Teräsvirta (2007). In addition, we utilize two Lagrange Multiplier (LM) tests that discriminate, on the one hand, between a constant correlation GARCH model and the STCC-GARCH model, and, on the other hand, between the STCCGARCH model and the DSTCC-GARCH model. In this way, we test whether none, one, or two structural changes have occurred in the time profile of business cycle synchronizations. With this methodology we are able to identify endogenously the time period of such changes, if any, and also characterize the transition path to the new regime in terms of its smoothness.

The main results suggest that conditional correlation patterns between the euro area and all the newly accessed member states and negotiating countries have substantially increased over the last two decades. Specifically, we find that correlations have more than tripled for the majority of

\footnotetext{
${ }^{2}$ Analogous issues arise when testing for change in the parameters of a regression equation, which has given rise to a substantial recent literature on the econometric analysis of structural change; see Andrews (1993) for a seminal contribution.
} 
the countries. These changes are generally abrupt and the dates of change vary widely across countries. Additionally, some of the new EU members exhibit business cycle correlations with the euro area that are comparable to the "core" EU states of France and Germany. A novel finding of our methodological approach is the generation of non-monotonic correlation patterns due to the existence of two structural changes in some of the countries. These are illustrated either by U-curved or hump-shaped co-movement patterns.

The rest of this paper is organized as follows. In the next section, we describe the data. Section 3 introduces the econometric methodology while section 4 presents the empirical results. Finally, section 5 offers some concluding remarks.

\section{Data}

We utilize monthly data on the seasonally adjusted industrial production index for each country and an aggregate euro area measure over the period January 1980 (or the earliest available) to June 2006. ${ }^{3,4}$ We exclude Latvia, Malta, and Bulgaria from our sample of new EU members and candidate countries due to data limitations. ${ }^{5}$ To obtain a measure of the cyclical component for each country, we detrend each data series using the Hodrick and Prescott filter. ${ }^{6}$ We work throughout with the logarithms of the series because we are mainly interested in percentage deviations from the trend. This method is appropriate to assess the relative magnitude of fluctuations.

We concentrate our analysis on nine enlargement countries (Cyprus, Czech Republic, Estonia, Hungary, Lithuania, Poland, Romania, Slovakia, and Slovenia) and on the countries which are in various stages of candidacy for membership (Croatia, FYROM, and Turkey). The data are extracted from the IMF international financial statistics (IFS) database with seasonally adjusted (SA) series obtained by applying the X-11 filter. The SA series for all countries are checked for

\footnotetext{
${ }^{3}$ Although quarterly GDP has been widely used to estimate the output gap, it is available for a very short time span, which is restrictive for the purpose of our study. Further, as Artis et al. (2004) note, industrial production indexes display more cyclical sensitivity than GDP estimates and hence may be more informative for monitoring business cycle fluctuations. Therefore, we prefer to base our analysis on industrial production index as is common in the literature. See Camacho et al. (2006) for a discussion of the advantages.

${ }^{4}$ In line with the recent evidence by Camacho et al. (2006), who do not find a country or set of countries that act as distinct euro-economy attractors, we utilise an aggregate measure to represent the euro area business cycle rather than use the cycle of a leading European economy, or the cycle of a weighted average of a subset of EMU economies. The euro area here is the "euro twelve", that is the twelve member countries prior to Slovenia joining the area.

${ }^{5}$ We were not able to identify data for Malta, while for Latvia (since 2001:1) and Bulgaria (since 2000:1) the data coverage period produces insufficient observations for a reliable analysis to be undertaken.

${ }^{6}$ We adopt the standard recommendation of the literature for monthly series and use a value of $\lambda=14,400$.
} 
outliers and outliers detected have been replaced using the median value of the \pm 3 observations. ${ }^{7}$ In the Appendix, Table A1 gives the exact time span of the country sample while Figure 1 depicts the time profile of the cyclical component of each country and of the EMU aggregate. Although our primary goal is to examine the business cycle correlation of new members with the EMU and identify potential structural changes over the period under investigation, we also include for comparison in our sample some of the "core" members of the euro area (Austria, Belgium, France, and the Netherlands) and its "periphery" countries (Greece, Ireland, Portugal, and Spain). ${ }^{8}$

Since we anticipate the implementation of monetary policy in the enlarged EMU to be more successful if the members have less volatile and more synchronized business cycles, we compare the compatibility of the recently acceded and negotiating countries' business cycles with that of the euro area.

\section{Econometric Methodology}

In this section we introduce a bivariate VAR-GARCH model proposed by Berben and Jansen (2005) and Silvennoinen and Teräsvirta (2005) that enables us to test the time-varying behavior of business cycle correlations ${ }^{9}$.

Consider a bivariate time series of cyclical components $\left\{y_{t}\right\}, t=1, \ldots, n, y_{t}=\left(y_{1, t}, y_{2, t}\right)^{\prime}$, the stochastic properties of which are assumed to be described by the following model

$$
y_{t}=c_{0}+\sum_{k=1}^{p} \phi^{k} y_{t-k}+\varepsilon_{t}
$$

where $\phi^{k}=\left[\begin{array}{ll}\phi_{11}^{\kappa} & \phi_{12}^{\kappa} \\ \phi_{21}^{\kappa} & \phi_{22}^{\kappa}\end{array}\right](k=1, \ldots, p)$ captures any possible own past effects and cross effects from one business cycle to the other. ${ }^{10}$ The error term is assumed to follow the process

\footnotetext{
${ }^{7}$ The X-11 filter and the outlier detection technique are applied with the GAUSS program made available by Mark Watson and outlined in Stock and Watson (2003). This program uses a fraction of an interquartile range with our threshold multiple set to 5. The SA series is used for outlier detection to avoid conflating outliers and seasonality.

${ }^{8}$ A set of diagnostic tests (available upon request) on the cyclical components, that includes a Ljung-Box test for up to twelve lags of serial correlation and its counterpart in the squared data, suggest strong presence of serial correlation and conditional heteroscedasticity. This implies that second moment nonlinear dependencies are significant, supporting the use of a GARCH specification that captures changes in volatility.

9 In practise neither Berben and Jansen (2005) nor Silvennoinen and Teräsvirta (2005) use any lags in their VAR specification.

${ }^{10}$ To determine the appropriate order, $p$, of equation (1) we use the Schwartz Infrormation Criterion for the maximum of 12 lags.
} 


$$
\varepsilon_{t} \mid \Psi_{t-1} \sim N\left(0, H_{t}\right)
$$

where $\Psi_{t-1}$ is the information set consisting of all relevant information up to and including time $t-1$, and $N$ denotes the bivariate normal distribution. The conditional covariance matrix of $\varepsilon_{t}$, $H_{t}$, is assumed to follow a time-varying structure given by

$$
\begin{gathered}
H_{t}=E\left[\varepsilon_{t} \varepsilon_{t}^{\prime} \mid \Psi_{t-1}\right], \\
h_{11, t}=\omega_{1}+\alpha_{1} \varepsilon_{1, t-1}^{2}+\beta_{1} h_{11, t-1}, \\
h_{22, t}=\omega_{2}+\alpha_{2} \varepsilon_{2, t-1}^{2}+\beta_{2} h_{22, t-1}, \\
h_{12, t}=\rho_{t}\left(h_{11, t} h_{22, t}\right)^{1 / 2}, \\
\rho_{t}=\rho_{0}\left(1-G\left(s_{t} ; \gamma, c\right)\right)+\rho_{1} G\left(s_{t} ; \gamma, c\right),
\end{gathered}
$$

where we assume that the conditional variances $h_{11, t}$ and $h_{22, t}$ both follow a $\operatorname{GARCH}(1,1)$ specification. Our choice is motivated by the heavy autocorrelation of the second moments, as indicated by the diagnostic tests, and by the empirical literature that has found that this specification adequately captures the persistence in second moments of industrial production indices (e.g., Fornari and Mele, 1997; Grier and Perry, 2000; Grier et al., 2004).

To capture temporal changes in the contemporaneous conditional correlation $\rho_{t}$ we follow Berben and Jansen (2005) and Silvennoinen and Teräsvirta (2005) by letting $G\left(s_{t} ; \gamma, c\right)$ be the logistic function

$$
G\left(s_{t} ; \gamma, c\right)=\frac{1}{1+\exp \left(-\gamma\left(s_{t}-c\right)\right)}, \quad \gamma>0
$$

where $s_{t}$ is the transition variable, and $\gamma$ and $c$ determine the smoothness and location, respectively, of the transition between the two correlation regimes ${ }^{11}$. The transition variable is described as a function of time: $s_{t}=t / n^{12}$.

\footnotetext{
${ }^{11}$ The transition function $G\left(s_{t} ; \gamma, c\right)$ is bounded between zero and one, so that, provided there are valid correlations lying between -1 and +1 , the conditional correlation $\rho_{t}$ will also lie between -1 and +1 .

${ }^{12}$ In practice, we scale $(t / n-c)$ by $\sigma_{t / n}$, the standard deviation of the transition function $t / n$, to make estimates of $\gamma$ comparable across different sample sizes. In principle, any variable can act as a transition variable.
} 
The resulting Smooth Transition Conditional Correlation (STCC) GARCH model is able to capture a wide variety of patterns of change. Differing $\rho_{0}$ and $\rho_{1}$ imply that the correlations monotonically increase $\left(\rho_{0}<\rho_{1}\right)$ or decrease $\left(\rho_{0}>\rho_{1}\right)$, with the pace of change determined by the slope parameter $\gamma$. This change is abrupt for large $\gamma$, and becomes a step function as $\gamma \rightarrow \infty$, with more gradual change represented by smaller values of this parameter. Finally, the location parameter $c$ indicates the mid-point of any time change. The constant conditional correlation model (Bollerslev, 1990) is a special case of the STCC-GARCH model, obtained by setting either $\rho_{0}=\rho_{1}$ or $\gamma=0$; Berben and Jansen (2005) provide a test for the STCC-GARCH model against the null of constant conditional correlations; see also Silvennoinen and Teräsvirta (2005, 2007).

Next, we examine whether another transition (in correlations) exists by performing a LM test developed by Silvennoinen and Teräsvirta (2007) ${ }^{13}$. If such evidence is found, then we extend the original STCC-GARCH model by allowing the conditional correlations to vary according to two transition variables. The time-varying correlation structure in the Double Smooth Transition Conditional Correlation (DSTCC) GARCH model is imposed through the following equation:

$$
\rho_{t}=\rho_{0}\left(1-G_{l}\left(s_{t} ; \gamma_{1}, c_{1}\right)\right)+\rho_{1} G_{l}\left(s_{t} ; \gamma_{1}, c_{1}\right)\left(1-G_{2}\left(s_{t} ; \gamma_{2}, c_{2}\right)\right)+\rho_{2} G_{l}\left(s_{t} ; \gamma_{1}, c_{1}\right) G_{2}\left(s_{t} ; \gamma_{2}, c_{2}\right),
$$

where each transition function has the logistic form of equation (8). Since we are interested in modeling temporal change, the second transition variable is also a function of time $\left(s_{t}=t / n\right)$, and hence (9) allows the possibility of a non-monotonic change in correlation over the sample. The parameters $\gamma_{i}$ and $c_{i}(i=1,2)$ are interpreted in the same manner as for the STCC-GARCH model, but to ensure identification we require $c_{1}<c_{2}$ and hence that the two correlation transitions occur at different points of time.

The likelihood function at time $t$ (ignoring the constant term and assuming normality) is given by

$$
l_{t}(\theta)=-\frac{1}{2} \ln \left|H_{t}\right|-\frac{1}{2} \varepsilon_{t}^{\prime} H_{t} \varepsilon_{t}
$$

where $\theta$ is the vector of all the parameters to be estimated. The log-likelihood for the whole sample from time 1 to $n, L(\theta)$, is given by

\footnotetext{
${ }^{13}$ For analytical expressions for the test statistics and the required derivatives, we refer to Silvennoinen and Teräsvirta (2007).
} 


$$
L(\theta)=\sum_{t=1}^{n} l_{t}(\theta)
$$

This log-likelihood is maximized with respect to all parameters simultaneously, employing numerical derivatives of the log-likelihood. To allow for non-normality of $\varepsilon_{t} \mid \Psi_{t-1}$, robust "sandwich" standard errors (Bollerslev and Wooldridge, 1992) are used for the estimated coefficients.

To verify the specification of the mean equation (1), we also test for the presence of temporal change in the coefficients $\phi^{k}$. This is achieved by testing against a model that allows the own past and cross effects from the business cycle of one country to the other to change through a time transition function of the form of (7)-(8), so that the alternative model to (1) takes the form:

$$
y_{t}=c_{0}+\sum_{k=1}^{p} \phi^{k} y_{t-k}+\left[c_{0}^{*}+\sum_{k=1}^{p} \phi^{k^{*}} y_{t-k}\right] G\left(s_{t} ; \gamma^{*}, c^{*}\right)+\varepsilon_{t} .
$$

This can be viewed as a robustness test for our findings relating to structural changes in the correlations, since misspecification of the mean equations by omitting structural changes that are present may lead to the apparent existence of structural change in the correlations (which are computed conditional on mean effects).

\section{Empirical Results}

In this section, we first look at the correlations of the full sample assuming that there is no regime switch within the covered time period. This also allows us to compare our results with those of the existing literature. Then, we apply a LM test to investigate whether a structural change has occurred in the correlations between the business cycles of new, candidate, "core", and "periphery" countries with the euro area members. This is accompanied by a heteroskedasticity consistent $F$-test that examines the presence of temporal change in the mean equation. Next, we estimate the STCC-GARCH model to determine the time and the pattern of the shifts. Finally, we apply a LM test to investigate whether another transition exists and, where appropriate, we extend the STCC-GARCH model and estimate the DSTCC-GARCH model with more than one transition regimes in correlations. 


\subsection{Full-sample single correlations}

Table 1 shows the correlations of the new, negotiating, core, and periphery countries with the euro area for three different time periods: the full coverage period, a period that ends in 2002, and a period that begins in 1995. Although the most relevant results come from the full sample period, we also report the other two sub-samples for the following reasons. First, we limit the end period to 2002 in order to conform to the data coverage of some studies, and because this date highlighted the end of the admission negotiation period of the 10 countries that eventually joined the EU in 2004. Second, the starting date of 1995 has been identified by many studies as important because official euro area membership applications of the recently acceded countries started at that time, but most significantly because the post-1995 period excludes the turbulent years of transition in the early 1990s for the CEECs. ${ }^{14}$

A number of observations deserve attention. First, the correlation estimates of the full sample and of the sample ending in 2002 appear to be materially unaltered. However, these similarities may mask endogenous changes in business cycle synchronization at a date after 2002 that are smoothed out when considering the entire sample. Second, for most CEECs the change in the sample to the post-1995 period shows an increase in their correlation coefficients - especially for Estonia, Hungary, and Poland - giving support to the claims that a sample period starting prior to 1995 may be biased due to transitional recessions. This becomes even more plausible when considering the relative constancy of the post-1995 correlation coefficients of the core and periphery EMU participants. Third, the degrees of co-movements appear to be consistent with the findings in the recent literature. For instance, Berger et al. (2002) and Artis et al. (2004) consider a similar detrending technique for industrial production during 1990-2001 and 1993-2002 respectively. Berger et al. (2003) find comparable correlations to our end-of-2002 sample estimates for Cyprus, Hungary, Poland, Romania, and Slovenia, while Artis et al. (2004) for Estonia, Hungary, Poland, Slovakia, and Slovenia. In both studies, the correlations for the remaining countries are somewhat smaller in magnitude. In a similar fashion, Boreiko (2003) and Firdmuc (2004) report for the 1996-2001 period results effectively identical to our last column of the post-1995 period.

Overall, the above results suggest that for the new and currently negotiating EU countries the findings in the literature depend heavily on the period under investigation. This, in turn, implies that there may be two (or more) trends in business cycle synchronization that highlight changes

\footnotetext{
${ }^{14}$ Time series tests of convergence that rely on periods where countries are far away from their steady state are criticized as not being reliable (see, for example, Bernard and Durlauf, 1996).
} 
in correlation regimes. Whether these changes occurred after 1995, after the end of the EU admission negotiations in 2002, or at any other point in time, however, needs to be tested rather than assumed in an ad-hoc manner. This is the way we proceed in the next sections where we endogenously determine the date and the speed of changes in regime shifts.

\subsection{Evaluation of structural changes}

To assess whether the proposed time-varying STCC-GARCH specification really improves the model's ability to track the time-series properties of the data over a fixed parameter version, we employ a Lagrange Multiplier (LM) test developed by Silvennoinen and Teräsvirta (2007). ${ }^{15}$ This test is designed to discriminate between the constant correlation GARCH model and the STCCGARCH model and is applied to the VAR residuals with order specified using the Schwartz Information Criterion (see below).

Under the null hypothesis, the LM statistic is asymptotically $\chi^{2}$ distributed with one degree of freedom. The LM test does not discriminate between an increase and a decrease in correlation. It simply tests the null hypothesis $\mathrm{H}_{0}: \gamma=0$ against the alternative of $\mathrm{H}_{\mathrm{a}}: \gamma>0$, which implies a time-varying conditional correlation. To determine whether the correlation has gone up or down, the STCC-GARCH model has to be estimated. As stated earlier, we assume that business cycles have time-varying conditional variances that follow a $\operatorname{GARCH}(1,1)$ specification. ${ }^{16}$

Table 2, column 2 reports the LM statistics. The test reveals that the null hypothesis of no structural change in the business cycle co-movements of each country with the euro area is rejected at least at the 5\% marginal level of significance. The only exception is Romania where the null is rejected at the $10 \%$ level. These results strongly support the notion of a regime switch in the synchronicity of cycles not only for the older members of the EU ("core" and "periphery"), but also for the most recent members and the negotiating nations. ${ }^{17}$

The presence of one structural change in the business cycle synchronization between each country and the euro area implies a monotonic relationship between calendar time and business cycle correlations. We next examine the existence of a second transition in time that allows for a

\footnotetext{
${ }^{15}$ We refer to Silvennoinen and Teräsvirta (2007) for an excellent description of the development and the details of this test.

${ }^{16}$ We establish the adequacy of the model specification by performing standardized residual diagnostic tests. The mean and variance of the standardized residuals are found to have values of zero and one respectively for all the economies. In addition, the Ljung-Box statistics in the standardized and squared standardized residuals show no evidence of linear dependence, suggesting that the model is well specified. These results are available upon request.

${ }^{17}$ To check the robustness of our results, we also performed a similar test developed by Berben and Jansen (2005). The results are qualitatively the same.
} 
non-monotonic relationship which can capture more complicated patterns in time-varying correlations using the LM test developed by Silvennoinen and Teräsvirta (2007). The results in Table 2, column 3 identify seven countries for which a second transition exists: Cyprus, Estonia, FYROM, Turkey, Belgium, Ireland, and the Netherlands. Among them, FYROM is the only country that the null is rejected at the $10 \%$ level of significance but not $5 \%$.

We also use a heteroscedasticity consistent $F$-test to examine the presence of temporal change in the mean, as in equation (1'). The test results, which are available upon request, indicate that only the equations for Hungary and Slovenia exhibit such change at a marginal level of significance less than $5 \%$. In all cases, the test applied to the euro area aggregate equation does not exhibit evidence of temporal change. Consequently, we conclude that (at least for the vast majority of countries examined), the evidence found of single and double structural change in the conditional correlations cannot be attributed to the inappropriate use of a constant parameter specification for the VAR mean equations.

These findings clearly emphasize that it is not reasonable to assume that contemporaneous business cycle correlations remain constant over the years, and that in some instances are characterized by more than two dominant trends. To examine the direction and the pattern of change(s), we turn next to the estimation of the STCC-GARCH and the DSTCC-GARCH models.

\subsection{Time-varying shifts in business cycle synchronization}

Based on the evidence provided by the LM tests, Tables 3 and 4 report the estimated parameters of the (D)STCC-GARCH models described in equations (1)-(9) for all the countries. Table 3 presents the VAR and GARCH parameters, while Table 4 describes the estimated parameter values of the transition function(s) and the conditional correlations that characterize the old, the interim (where appropriate), and the new regimes in (7)-(9).

Starting with Table 3, the VAR parameters $\phi_{i j}^{k}$, where $i, j=1,2$ and $k=1,2,3,4$, capture the own country (for $i=j$ ) and transmission $(i \neq j)$ dynamics for the business cycle, with $i=1$ being the individual country and $i=2$ the euro area. ${ }^{18}$ The table shows that the VAR lag order $p$, determined by the Schwartz Information Criterion using a maximum of 12 lags, is never more

\footnotetext{
${ }^{18}$ For example, $\phi_{12}^{2}$ describes the two period lagged effect of the euro area business cycle on the current business cycle of each country.
} 
than four. It is also clear from the table that the own business cycle lagged effects are significant both for each individual country $\left(\phi_{11}^{k}\right)$ and for the euro area $\left(\phi_{22}^{k}\right)$, reflecting the importance of business cycle dynamics.

In a similar way, the euro area business cycle substantially affects the business cycle of most other countries, as illustrated by the positive sign and significance of the parameters $\phi_{12}^{k}$. This could be due to the higher trade, financial, and economic integration that the EU offers to its members, thus influencing the profile of their domestic business cycles. This has also been supported by Firdmuc (2004), who finds that since the mid-1990s the business cycle of the EU has greatly determined the developments in the CEECs' economies. However, this effect is more marked for the recently acceded than the negotiating countries, with the euro area cycle playing no significant role for the latter - except for FYROM. Finally, note that the past cyclical effects of the recently acceded and negotiating countries do not typically affect the cyclical behavior of the euro area industrial production index as indicated by the parameters $\phi_{21}^{k}$. This is not surprising since it reflects the relatively small role of these new member countries in determining the overall euro area business cycle. Indeed, of the "core" countries, only Austria and Germany have positive and significant lagged effects on the euro area cycle.

As far as the coefficients of the conditional covariance matrix of $\varepsilon_{t}$ are concerned, the significance of the estimates of $\alpha_{i}$ and $\beta_{i}$ suggest that the $\operatorname{GARCH}(1,1)$ specification we have utilized captures the changing conditional volatility of the business cycle in these countries. More specifically, the volatilities of business cycles of most countries are characterized by both short and long term persistency as indicated by the joint significance of $\alpha_{1}$ and $\beta_{1}$. However, the behavior of the volatility of the business cycle of the euro area is mainly influenced by either short $\left(\alpha_{2}\right)$ or long term $\left(\beta_{2}\right)$ persistency in most of the combinations.

Turning our attention to the examination of the transition functions, Table 4 reports the conditional correlations in the original $\left(\rho_{0}\right)$, the interim - where appropriate $-\left(\rho_{1}\right)$, and the new ( $\rho_{1}$ or $\left.\rho_{2}\right)$ regimes, the locations of the transitions $\left(c_{1}\right.$ and/or $\left.c_{2}\right)$, the shape of the transitions $\left(\gamma_{1}\right.$ and/or $\gamma_{2}$ ), and, finally, the central date(s) of the implied structural change(s) over our sample period. ${ }^{19}$ Note that the inflection points represented by $c_{i}, i=1,2$, are expressed as fractions of

\footnotetext{
${ }^{19}$ Of course, for the seven countries that the LM test identified a second structural change in the correlations, $\rho_{1}$ represents the interim regime and $\rho_{2}$ the new regime, while for the remaining countries $\rho_{1}$ depicts the new regime.
} 
the sample size, with the reported month of structural change then corresponding to the estimated $c_{i}$.

The main finding that emerges from Table 4 is that all the countries - new EU members, negotiating, core, and periphery states - experienced an increase in their business cycle synchronization with the euro area. The increase in correlation from the old to the new regime has been quite substantial in all cases, in particular for the recently acceded nations. For Romania the correlation changed from negative and small to positive, while the correlations more than tripled for all others except Estonia, Slovakia, and Slovenia, and for these three it more than doubled. $^{20}$ Indeed, with the single exception of Romania, the conditional correlations for the recently acceded countries with the euro area are around 0.5 or more in the new regime. The correlations also increased over the period for the negotiating countries, but those for FYROM and Turkey remain relatively low, indicating their business cycles are much further from synchronization with the euro area than are the acceding countries.

A distinctive feature of our results is the generation of some non-monotonic correlation patterns due to the existence of two structural changes and, therefore, three distinct correlation regimes. Table 4 shows that Cyprus, Estonia, and FYROM have experienced a U-curved pattern with an initial decline and a subsequent increase in correlations, while Turkey, Belgium, and the Netherlands depicted a hump-shaped pattern with initial increases followed by declines. Finally, Ireland has demonstrated a twice increasing correlation pattern generating a stepwise process.

It is interesting that for some countries (Cyprus, the Czech Republic, Hungary, Lithuania, Poland, and Croatia) the regime switch has been so large that they attained correlation patterns similar not only to periphery EMU members, but also to some core states (Austria, France, and Germany). ${ }^{21}$ A similar picture is obtained for the periphery euro area states that have been catching-up with the core members for a number of years. Their synchronization with the euro area cycle more than doubled (in Ireland's case it changed from negative and small to around 0.5 ) and reached levels equivalent to some core countries, for which co-movements have also increased overall.

\footnotetext{
${ }^{20}$ Nevertheless, the estimated values of the correlations should be treated with some caution when there are relatively few sample observations beyond the estimated date of change. In this context, the high correlations of 0.890 and 0.987 for Lithuania and Croatia, respectively, with the euro area in the new regime may partially reflect the relatively small post-structural break samples on which these are based.

${ }^{21}$ Lithuania deserves special reference since the majority of the studies have found that it exhibits very low or even negative correlation. That appears to also be the case in our analysis, but it restricts itself only in the first regime.
} 
As regards the dates of change $\left(c_{i}\right)$ and the lengths of the transition periods implied by $\gamma_{i}$, the results point to a great variety across countries. However, it seems that for the majority of countries the transition has been quite swift. Apart from a few countries (the Czech Republic, Poland, Croatia, Portugal, and Spain) the large values of $\gamma_{i}$ suggest the abrupt changes in correlation regimes. In addition, the dates of the structural changes for most of the new EU members (Cyprus, the Czech Republic, Estonia, Lithuania, Poland, Romania, and Slovakia) occurred around or after the completion of their admission negotiations at the end of 2002. The remaining states (Hungary and Slovenia) showed a change in correlations at the second half of the 1990s. From a methodological point of view, the finding of large differences in dates and pace of structural changes illustrates the advantages of having a testing procedure that endogenously determines change points.

These findings can be justified on the grounds of higher trade and financial integration between the EU and its associated states (e.g., Firdmuc, 2004; Furceri and Karras, 2006). They suggest, however, that the tendency toward greater business cycle co-movement is not solely governed by EU-related developments but that country-specific factors also played a significant role. They are also in line with the related literature, which shows a higher level of business cycle compatibility between the EU, on the one hand, and Hungary and Slovenia, on the other. These countries appear to have been ready to join the EU sooner than their counterparts which eventually entered the EU in 2004, as evident by the increase in their correlations as early as the mid- and late-1990s respectively. These results can be also viewed in Figure 2, which presents graphical illustrations of the shape and smoothness of the transition function. ${ }^{22}$

As noted in subsection 4.2 above, the VAR equations for Hungary and Slovenia exhibit evidence of structural change. Although (for comparability with other countries) the results in Tables 3 and 4 do not allow for these structural changes, their inclusion in the mean equations do not substantially affect the results shown for Hungary and Slovenia. Consequently, this does not alter the main outcomes of our regime-switching approach and provides support to our findings that the contemporaneous conditional correlation, $\rho_{t}$, represents the primary (statistical) driver of increased integration.

\footnotetext{
${ }^{22}$ For space considerations, we do not report in Figure 2 the old members of the EMU (core and periphery states). Plots are available upon request.
} 


\section{Conclusions}

This paper examines business cycle synchronizations between the euro area and the new and candidate countries of the EU. The issue itself is by no means novel, nor the examination of the countries under consideration. The benefits and costs of a currency union have been extensively analyzed in the literature in the pioneering works of Mundell (1961), McKinnon (1963), and Kenen (1969), and more recently by Bayoumi and Eichengreen (1996), Frankel and Rose (1998), and Rose (2000). Moreover, a number of recent papers examined the above issue for newly accepted EU states, among them, Berger et al. (2002), Artis et al. (2004), Firdmuc (2004), Darvas and Szapáry (2005), Furceri and Karras (2006), and Firdmuc and Korhonen (2006).

The main innovation of our paper lies in the methodological technique we utilize that allows for structural changes in the degree of co-movement between the cyclical components of industrial production. This novel technique allows us to identify the time periods at which the changes occur and at the same time describes the lengths of the transition phases. The advantage of this procedure is that we endogenously determine the dates of the regime switches instead of setting them in an ad-hoc manner. In this way, we avoid the statistical deficiencies associated with the exogenous setting of date of change that biases other approaches in the literature.

The formulation of our model is based on a bivariate VAR-GARCH specification with a single and double smoothly time-varying correlation (STCC- and DSTCC-GARCH). The VAR specification filters out dynamic effects and enables us to focus on changes in the synchronous business cycle correlations. To examine the presence of structural change, we first use a Lagrange Multiplier (LM) statistic that tests the constant correlation hypothesis in the business cycles of the euro area and nine recent EU members and three of its negotiating countries. We then examine the existence of a second transition in time that allows for a non-monotonic relationship. Once we establish the occurrence of such temporal change, we then use our models to investigate in more detail the characteristics of the regime shifts.

We find that all the countries - new EU members, negotiating, core, and periphery states experienced a sizeable increase in their business cycle synchronization with the euro area. For some countries the regime switch has been so large that they attained correlation patterns similar not only to periphery euro area members, but also to some core states. A distinctive feature of our results is the generation of non-monotonic correlation patterns due to the existence of two structural changes and, therefore, three distinct correlation regimes for seven of the countries. 
Our results point to great variety in the timing and speed of the correlation shifts across our country sample. For the majority of the countries we identify an abrupt transition to the new regime. The dates of the structural change also seem to differ with most of the new EU members experiencing a change around or after the completion of their admission negotiations at the end of 2002. As such, only Hungary and Slovenia have been better prepared in joining the EU sooner than 2004 since their regime shifts took place well before 2002. These findings are consistent with the notion that the structural shifts toward a greater degree of synchronization between the EU and its associate states is not solely driven by EU-related factors, but that country-specific factors also have a substantial impact. Relevant country-specific factors may include differences in trade transaction costs and information costs as a result of differences in exchange rate regimes and the domestic use of the euro prior to EU accession.

Our findings, on the one hand, provide a critical view in past works that do not consider a flexible approach to modeling structural changes. On the other hand, however, provide support to the general conclusions in the literature. Therefore, we consider our modeling strategy as a step forward in the examination of business cycle co-movements. 


\section{References}

Andrews, D.W.K. 1993. Tests for parameter instability and structural change with unknown change point. Econometrica, 61, 821-856.

Angeloni, I and Debola, L. 1999. From the ERM to the Euro: New evidence on economic and policy convergence among EU countries. European Central Bank working paper, Frankfurt.

Artis, M. 2003. Is there a European business cycle? CESifo working paper no. 1053, Munich.

Artis, M., Marcellino, M., and Proietti, T. 2004. Characterizing the business cycle for accession countries. CEPR discussion paper no. 4457, London.

Bayoumi, T., and Eichengreen, B. 1996. Operationalising the theory of optimum currency areas. CEPR discussion paper no. 1484, London.

Berben, R-P., and Jansen, W.J. 2005. Comovement in international equity markets: A sectoral view. Journal of International Money and Finance, 24, 832-857.

Berger, H., de Haan, J., and Inklaar, R. 2002. Restructuring the ECB. CESifo working paper no. 1084, Munich.

Bernard, A.B., and Durlauf, S.N. 1996. Interpreting tests of the convergence hypothesis. Journal of Econometrics, 71, 161-173.

Bollerslev, T. 1990. Modelling the coherence in short-run nominal exchange rates: A multivariate generalized ARCH approach. Review of Economics and Statistics, 72, 498505.

Bollerslev, T., and Wooldridge, J.M. 1992. Quasi-maximum likelihood estimation and inference in dynamic models with time-varying covariances. Econometric Reviews, 143-172.

Boreiko, D. 2003. EMU and accession countries: Fuzzy cluster analysis of membership. International Journal of Finance and Economics, 8, 309-325.

Boyer, B.H., Gibson, M.S. and M. Loretan 1999. Pitfalls in tests for changes in correlations. Board of Governors of the Federal Reserve System, International Finance Discussion Paper No. 597 (revised version).

Camacho, M., Perez-Quiros, G., and Saiz, L. 2006. Are European business cycles close enough to be just one? Journal of Economic Dynamics and Control, 30, 1687-1706.

Clarida, R., Gali, J., and Gertler, M. 1999. The science of monetary policy: A New Keynesian perspective. Journal of Economic Literature, 37, 1661-1707.

Darvas, Z., and Szapáry, G. 2005. Business cycle synchronization in the enlarged EU. CEPR discussion paper no. 5179, London.

Firdmuc, J. 2004. The endogeneity of the optimum currency area criteria, intra-industry trade, and EMU enlargement. Contemporary Economic Policy, 22, 1-12. 
Firdmuc, J., and Korhonen, I. 2006. Meta-analysis of the business cycle correlation between the euro area and the CEECs. Journal of Comparative Economics, 34, 518-537.

Firdmuc, J., and Korhonen, I. 2004. The euro goes East: Implications of the 2002 economic slowdown for synchronization of business cycles between the euro area and CEECs. Comparative Economic Studies, 46, 45-62.

Fornari, F., and Mele, A. 1997. Asymmetries and non-linearities in economic activity. Applied Financial Economics, 7, 203-206.

Frankel, J.A., and Rose, A.K. 1998. The endogeneity of the optimum currency area criteria. Economic Journal, 108, 1009-1025.

Furceri, D., and Karras, G. 2006. Are the new EU members ready for the EURO? A comparison of costs and benefits. Journal of Policy Modeling, 28, 25-38.

Grier, K.B., Henry, Ó.T., Olekalns, N., and Shields, K. 2004. The asymmetric effects of uncertainty on inflation and output growth. Journal of Applied Econometrics, 19, 551-565.

Grier, K.B., and Perry, M.J. 2000. The effects of real and nominal uncertainty on inflation and output growth: Some GARCH-M evidence. Journal of Applied Econometrics, 15, 45-58.

Kenen, P.B. 1969. The optimum currency area: An eclectic view. In Mundell, R.A., and Swoboda, A. (Eds.), Monetary Problems of the International Economy. University of Chicago Press, Chicago.

Kočenda, E. 2001. Macroeconomic convergence in transition economies. Journal of Comparative Economics, 29, 1-23.

Koopman, S.J., and Azevedo, J. 2007. Measuring synchronization and convergence of business cycles for the Euro area, U.K. and U.S. Oxford Bulletin of Economics and Statistics, forthcoming.

Korhonen, I. 2003. Some empirical tests on the integration of economic activity between the euro area and the accession countries: A note. Economics of Transition, 11, 1-20.

Kutan, A.M., and Yigit, T. 2004. Nominal and real stochastic convergence of transition economies. Journal of Comparative Economics, 32, 23-36.

McKinnon, R. 1963. Optimum currency areas. American Economic Review, 53, 717-725.

Mundell, R.A. 1961. A theory of optimum currency areas. American Economic Review, 51, 657665.

Rogoff, K. 1985. The optimal degree of commitment to intermediate monetary target. Quarterly Journal of Economics, 100, 1169-1190.

Rose, A.K. 2000. One money, one market: Estimating the effect of common currencies on trade. Economic Policy, 30, 7-33. 
Silvennoinen A. and Teräsvirta T. 2005. Multivariate autoregressive conditional heteroskedasticity with smooth transitions in conditional correlations, SSE/EFI Working Paper Series in Economics and Finance No. 577.

Silvennoinen, A., and Teräsvirta, T. 2007. Modelling multivariate autoregressive conditional heteroskedasticity with the double smooth transition conditional correlation GARCH model. SSE/EFI working paper no. 652, Stockholm.

Stock, J.H., and Watson, M.W. 2003. Forecasting output and inflation: the role of asset prices. Journal of Economic Literature, 41, 788-829. 
Table 1: Sample Correlations with the Euro Area

\begin{tabular}{|c|c|c|c|c|}
\hline Country & Sample period & Full period & Ending 2002:12 & Starting 1995:1 \\
\hline \multicolumn{5}{|l|}{ Recently Acceded } \\
\hline Cyprus & 1988:1-2006:6 & 0.31 & 0.34 & 0.07 \\
\hline Czech Republic & 1993:1-2006:6 & 0.48 & 0.45 & 0.50 \\
\hline Estonia & $1994: 1-2005: 12$ & 0.36 & 0.37 & 0.48 \\
\hline Hungary & $1985: 1-2006: 6$ & 0.26 & 0.26 & 0.68 \\
\hline Lithuania & 1997-1:2006:6 & 0.22 & 0.17 & 0.22 \\
\hline Poland & 1985:1-2006:6 & 0.15 & 0.12 & 0.49 \\
\hline Romania & 1990:5-2006:6 & -0.009 & -0.019 & -0.11 \\
\hline Slovakia & 1993:1-2006:6 & 0.41 & 0.42 & 0.38 \\
\hline Slovenia & 1993:1-2006:6 & 0.66 & 0.66 & 0.54 \\
\hline \multicolumn{5}{|l|}{ Negotiating } \\
\hline Croatia & 1991:1-2006:6 & -0.06 & -0.06 & 0.18 \\
\hline FYROM & $1993: 1-2005: 12$ & 0.05 & 0.11 & 0.10 \\
\hline Turkey & $1985: 1-2006: 6$ & -0.001 & -0.031 & 0.36 \\
\hline \multicolumn{5}{|l|}{ Core } \\
\hline Austria & 1980:1-2006:6 & 0.63 & 0.63 & 0.72 \\
\hline Belgium & $1980: 1-2006: 6$ & 0.48 & 0.48 & 0.64 \\
\hline France & 1980:1-2006:6 & 0.48 & 0.46 & 0.81 \\
\hline Germany & 1980:1-2006:6 & 0.86 & 0.87 & 0.87 \\
\hline Netherlands & 1980:1-2006:6 & 0.42 & 0.42 & 0.33 \\
\hline \multicolumn{5}{|l|}{ Periphery } \\
\hline Greece & 1995:1-2006:6 & 0.38 & 0.40 & 0.38 \\
\hline Ireland & 1980:1-2006:6 & 0.35 & 0.36 & 0.43 \\
\hline Portugal & $1980: 1-2006: 6$ & 0.17 & 0.17 & 0.15 \\
\hline Spain & $1980: 1-2006: 5$ & 0.58 & 0.67 & 0.60 \\
\hline
\end{tabular}


Table 2: Tests for Smooth Transition Conditional Correlation

\begin{tabular}{|c|c|c|}
\hline Country & Single vs. Constant & Double vs. Single \\
\hline \multicolumn{3}{|l|}{ Recently Acceded } \\
\hline Cyprus & $14.913^{\star \star *}$ & $5.65^{\star \star}$ \\
\hline Czech Republic & $16.415^{\star \star \star}$ & 0.430 \\
\hline Estonia & $31.562^{\star \star *}$ & $6.026^{\star *}$ \\
\hline Hungary & $8.454^{\star \star *}$ & 1.109 \\
\hline Lithuania & $32.01^{\star * *}$ & 0.926 \\
\hline Poland & $48.644^{\star \star *}$ & 2.212 \\
\hline Romania & $9.534^{\star \star \star}$ & 0.043 \\
\hline Slovakia & $3.412^{*}$ & 1.410 \\
\hline Slovenia & $13.647^{\star \star *}$ & 0.393 \\
\hline \multicolumn{3}{|l|}{ Negotiating } \\
\hline Croatia & $4.408^{\star \star}$ & 0.120 \\
\hline FYROM & $4.759^{\star \star}$ & $3.772^{*}$ \\
\hline Turkey & $11.595^{\star \star *}$ & $5.618^{\star \star}$ \\
\hline \multicolumn{3}{|l|}{ Core } \\
\hline Austria & $5.232^{\star \star}$ & 0.029 \\
\hline Belgium & $20.656^{\star \star *}$ & $9.058^{* \star *}$ \\
\hline France & $5.910^{\star \star}$ & 2.620 \\
\hline Germany & $7.454^{\star \star \star}$ & 0.087 \\
\hline Netherlands & $21.166^{\star \star \star}$ & $6.472^{\star \star}$ \\
\hline \multicolumn{3}{|l|}{ Periphery } \\
\hline Greece & $6.315^{\star \star}$ & 0.483 \\
\hline Ireland & $45.746^{\star \star *}$ & $9.956^{\star \star \star}$ \\
\hline Portugal & $21.463^{\star \star *}$ & 0.005 \\
\hline Spain & $18.442^{\star \star *}$ & 0.117 \\
\hline
\end{tabular}

Notes: The values shown are LM test statistics for a smooth transition conditional correlation model against the null hypothesis of a constant conditional correlation (column2) and a double smooth transition model against the null hypothesis of a single transition model (column 3), with time as the transition variable in both cases; see Silvennoinen and Teräsvirta (2007). Under the null hypothesis the statistics are asymptotically distributed as $\chi^{2}$ with 1 degree of freedom; *, **, *** denote significance at $10 \%, 5 \%$ and $1 \%$, respectively. 
Table 3: Estimates of VAR and GARCH Parameters

Country's Coefficients

Euro Area Coefficients

\begin{tabular}{|c|c|c|c|c|c|c|c|c|c|c|c|c|c|c|c|c|c|c|c|c|c|c|c|c|c|}
\hline $\begin{array}{c}\text { Country with } \\
\text { Euro Area }\end{array}$ & $\begin{array}{l}\text { VAR } \\
\text { order }\end{array}$ & $c_{01}$ & $\phi_{11}^{(1)}$ & $\phi_{11}^{(2)}$ & $\phi_{11}^{(3)}$ & $\phi_{11}^{(4)}$ & $\phi_{12}^{(1)}$ & $\phi_{12}^{(2)}$ & $\phi_{12}^{(3)}$ & $\phi_{12}^{(4)}$ & $\omega_{1}$ & $\alpha_{1}$ & $\beta_{1}$ & $c_{02}$ & $\phi_{21}^{(1)}$ & $\phi_{21}^{(2)}$ & $\phi_{21}^{(3)}$ & $\phi_{21}^{(4)}$ & $\phi_{22}^{(1)}$ & $\phi_{22}^{(2)}$ & $\phi_{22}^{(3)}$ & $\phi_{22}^{(4)}$ & $\omega_{2}$ & $\alpha_{2}$ & $\beta_{2}$ \\
\hline \multicolumn{26}{|l|}{ Recently Acceded } \\
\hline Cyprus & 2 & -0.054 & 0.161 & 0.239 & - & - & -0.424 & 0.656 & - & - & 0.287 & 0.095 & 0.868 & 0.010 & -0.002 & -0.007 & - & - & 0.653 & 0.243 & - & - & 0.429 & 0.051 & 0.001 \\
\hline Czech Rep. & 2 & -0.019 & 0.285 & 0.233 & - & - & 0.765 & -0.302 & - & - & 0.346 & 0.001 & 0.917 & -0.001 & -0.024 & 0.012 & - & - & 0.663 & 0.219 & - & - & 0.005 & 0.002 & 0.989 \\
\hline Estonia & 3 & -0.109 & 0.131 & 0.019 & 0.392 & - & 0.548 & 0.846 & -1.008 & - & 0.001 & 0.033 & 0.962 & 0.028 & 0.001 & -0.001 & 0.016 & - & 0.633 & 0.169 & 0.048 & - & 0.004 & 0.001 & 0.989 \\
\hline Hungary & 0 & 0.132 & - & - & - & - & - & - & - & - & 0.878 & 0.173 & 0.726 & 0.165 & - & - & - & - & - & - & - & - & 0.588 & 0.578 & 0.001 \\
\hline Lithuania & 1 & -0.238 & 0.404 & - & - & - & 0.314 & - & - & - & 0.559 & 0.040 & 0.938 & 0.033 & -0.015 & - & - & - & 0.787 & - & - & - & 0.417 & 0.262 & 0.001 \\
\hline Poland & 4 & -0.041 & 0.296 & 0.259 & 0.307 & -0.196 & 0.014 & 1.142 & -0.486 & -0.691 & 0.893 & 0.189 & 0.725 & 0.013 & -0.022 & 0.014 & 0.037 & -0.026 & 0.421 & 0.412 & 0.168 & -0.119 & 0.134 & 0.033 & 0.728 \\
\hline Romania & 2 & 0.145 & 0.614 & 0.143 & - & - & 0.062 & 0.131 & - & - & 0.306 & 0.111 & 0.858 & 0.022 & 0.001 & 0.020 & - & - & 0.552 & 0.332 & - & - & 0.268 & 0.003 & 0.481 \\
\hline Slovakia & 2 & -0.053 & 0.341 & 0.166 & - & - & -0.089 & 0.563 & - & - & 0.163 & 0.012 & 0.948 & -0.002 & -0.012 & -0.036 & - & - & 0.634 & 0.277 & - & - & 0.001 & 0.004 & 0.997 \\
\hline Slovenia & 2 & -0.031 & 0.393 & -0.052 & - & - & 0.611 & -0.015 & - & - & 0.665 & 0.134 & 0.646 & -0.008 & 0.058 & 0.058 & - & - & 0.508 & 0.250 & - & - & 0.006 & 0.008 & 0.988 \\
\hline \multicolumn{26}{|l|}{ Negotiating } \\
\hline Croatia & 1 & -0.029 & 0.392 & - & - & - & 0.113 & - & - & - & 0.842 & 0.141 & 0.777 & 0.008 & -0.026 & - & - & - & 0.879 & - & - & - & 0.443 & 0.011 & 0.003 \\
\hline FYROM & 1 & -0.316 & 0.320 & - & - & - & 0.461 & - & - & - & 20.80 & 0.404 & 0.002 & -0.013 & 0.013 & - & - & - & 0.764 & - & - & - & 0.146 & 0.002 & 0.074 \\
\hline Turkey & 2 & -0.003 & 0.221 & 0.319 & - & - & -0.313 & 0.154 & - & - & 3.30 & 0.075 & 0.690 & 0.011 & 0.022 & -0.015 & - & - & 0.452 & 0.412 & - & - & 0.198 & 0.122 & 0.548 \\
\hline \multicolumn{26}{|l|}{ Core } \\
\hline Austria & 3 & 0.010 & 0.137 & 0.009 & 0.225 & - & 0.416 & 0.256 & -0.105 & - & 0.055 & 0.001 & 0.976 & -0.007 & 0.048 & 0.040 & -0.013 & - & 0.371 & 0.252 & 0.165 & - & 0.302 & 0.192 & 0.408 \\
\hline Belgium & 1 & -0.013 & 0.139 & 0.182 & - & - & 0.442 & 0.008 & - & - & 0.388 & 0.097 & 0.795 & -0.003 & -0.022 & 0.018 & - & - & 0.686 & 0.166 & - & - & 0.443 & 0.246 & 0.057 \\
\hline France & 2 & -0.028 & 0.304 & 0.186 & - & - & 0.169 & 0.113 & - & - & 0.180 & 0.142 & 0.718 & -0.022 & -0.034 & 0.029 & - & - & 0.635 & 0.237 & - & - & 0.138 & 0.171 & 0.619 \\
\hline Germany & 2 & -0.024 & 0.365 & 0.101 & - & - & 0.209 & 0.278 & - & - & 1.548 & 0.077 & 0.001 & -0.015 & 0.163 & -0.048 & - & - & 0.300 & 0.410 & - & - & 0.310 & 0.095 & 0.501 \\
\hline Netherlands & 2 & -0.021 & 0.119 & 0.073 & - & - & 0.595 & -0.275 & - & - & 0.020 & 0.032 & 0.962 & -0.012 & -0.046 & 0.011 & - & - & 0.651 & 0.215 & - & - & 0.448 & 0.193 & 0.065 \\
\hline \multicolumn{26}{|l|}{ Periphery } \\
\hline Greece & 1 & -0.021 & 0.417 & - & - & - & 0.314 & - & - & - & 0.139 & 0.001 & 0.955 & 0.006 & 0.045 & - & - & - & 0.726 & - & - & - & 0.532 & 0.075 & 0.001 \\
\hline Ireland & 2 & -0.030 & 0.211 & 0.189 & - & - & 0.384 & -0.072 & - & - & 4.833 & 0.183 & 0.426 & -0.009 & -0.008 & 0.001 & - & - & 0.660 & 0.197 & - & - & 0.412 & 0.255 & 0.076 \\
\hline Portugal & 2 & -0.055 & 0.250 & 0.269 & - & - & -0.097 & 0.187 & - & - & 1.001 & 0.075 & 0.738 & -0.010 & -0.016 & -0.022 & - & - & 0.639 & 0.218 & - & - & 0.400 & 0.225 & 0.124 \\
\hline Spain & 2 & -0.002 & 0.306 & 0.318 & - & - & 0.177 & -0.095 & - & - & 1.504 & 0.277 & 0.139 & 0.004 & 0.070 & 0.012 & - & - & 0.541 & 0.202 & - & - & 0.526 & 0.154 & 0.009 \\
\hline
\end{tabular}

Notes: statistically significant coefficients (at a marginal significance level of $10 \%$ or less) appear in bold type. 
Table 4: Estimates of the Transition Function(s) on Correlation Regimes

\begin{tabular}{|c|c|c|c|c|c|c|c|c|c|}
\hline $\begin{array}{c}\text { Country with } \\
\text { Euro Area }\end{array}$ & $\rho_{0}$ & $\rho_{1}$ & $\rho_{2}$ & $\boldsymbol{c}_{1}$ & $Y_{1}$ & $c_{2}$ & $Y_{2}$ & $\begin{array}{c}\text { Date of } 1^{\text {st }} \\
\text { Change }\end{array}$ & $\begin{array}{c}\text { Date of } 2^{\text {nd }} \\
\text { Change }\end{array}$ \\
\hline \multicolumn{10}{|l|}{ Recently Acceded } \\
\hline Cyprus & 0.185 & -0.527 & 0.618 & 0.669 & 500 & 0.742 & 3.725 & $2000-3$ & $2001-7$ \\
\hline Czech Rep. & 0.199 & 0.613 & - & 0.777 & 12.71 & - & - & $2003-5$ & - \\
\hline Estonia & 0.228 & -0.998 & 0.528 & 0.700 & 24.49 & 0.749 & 500 & $2002-3$ & $2002-10$ \\
\hline Hungary & 0.090 & 0.654 & - & 0.442 & 140.46 & - & - & $1994-7$ & - \\
\hline Lithuania & 0.182 & 0.890 & - & 0.941 & 500 & - & - & $2005-9$ & - \\
\hline Poland & 0.096 & 0.614 & - & 0.886 & 15.39 & - & - & $2003-9$ & - \\
\hline Romania & -0.079 & 0.265 & - & 0.709 & 500 & - & - & $2001-9$ & - \\
\hline Slovakia & 0.217 & 0.502 & - & 0.778 & 500 & - & - & $2003-5$ & - \\
\hline Slovenia & 0.194 & 0.482 & - & 0.347 & 500 & - & - & $1998-1$ & - \\
\hline \multicolumn{10}{|l|}{ Negotiating } \\
\hline Croatia & 0.068 & 0.987 & - & 0.915 & 3.715 & - & - & $2005-2$ & - \\
\hline FYROM & -0.109 & -0.712 & 0.090 & 0.300 & 18.16 & 0.341 & 55.50 & 1996-11 & $1997-5$ \\
\hline Turkey & -0.122 & 0.362 & 0.153 & 0.485 & 427.95 & 0.868 & 500 & $1995-4$ & $2003-7$ \\
\hline \multicolumn{10}{|l|}{ Core } \\
\hline Austria & 0.239 & 0.637 & - & 0.678 & 500 & - & - & 1997-8 & - \\
\hline Belgium & 0.208 & 0.731 & 0.542 & 0.650 & 500 & 0.908 & 54.81 & $1997-2$ & 2003-11 \\
\hline France & 0.528 & 0.740 & - & 0.603 & 500 & - & - & 1995-11 & - \\
\hline Germany & 0.658 & 0.834 & - & 0.672 & 332.22 & - & - & $1997-9$ & - \\
\hline Netherlands & 0.295 & 0.881 & 0.379 & 0.363 & 500 & 0.414 & 500 & $1989-7$ & $1990-11$ \\
\hline \multicolumn{10}{|l|}{ Periphery } \\
\hline Greece & 0.100 & 0.659 & - & 0.815 & 500 & - & - & $2004-4$ & - \\
\hline Ireland & -0.064 & 0.324 & 0.514 & 0.182 & 500 & 0.811 & 500 & 1984-10 & $2001-6$ \\
\hline Portugal & 0.155 & 0.567 & - & 0.873 & 38.00 & - & - & 2003-1 & - \\
\hline Spain & 0.383 & 0.745 & - & 0.425 & 22.46 & - & - & 1991-3 & - \\
\hline
\end{tabular}




\section{Appendix}

Table A1: Data Period Coverage

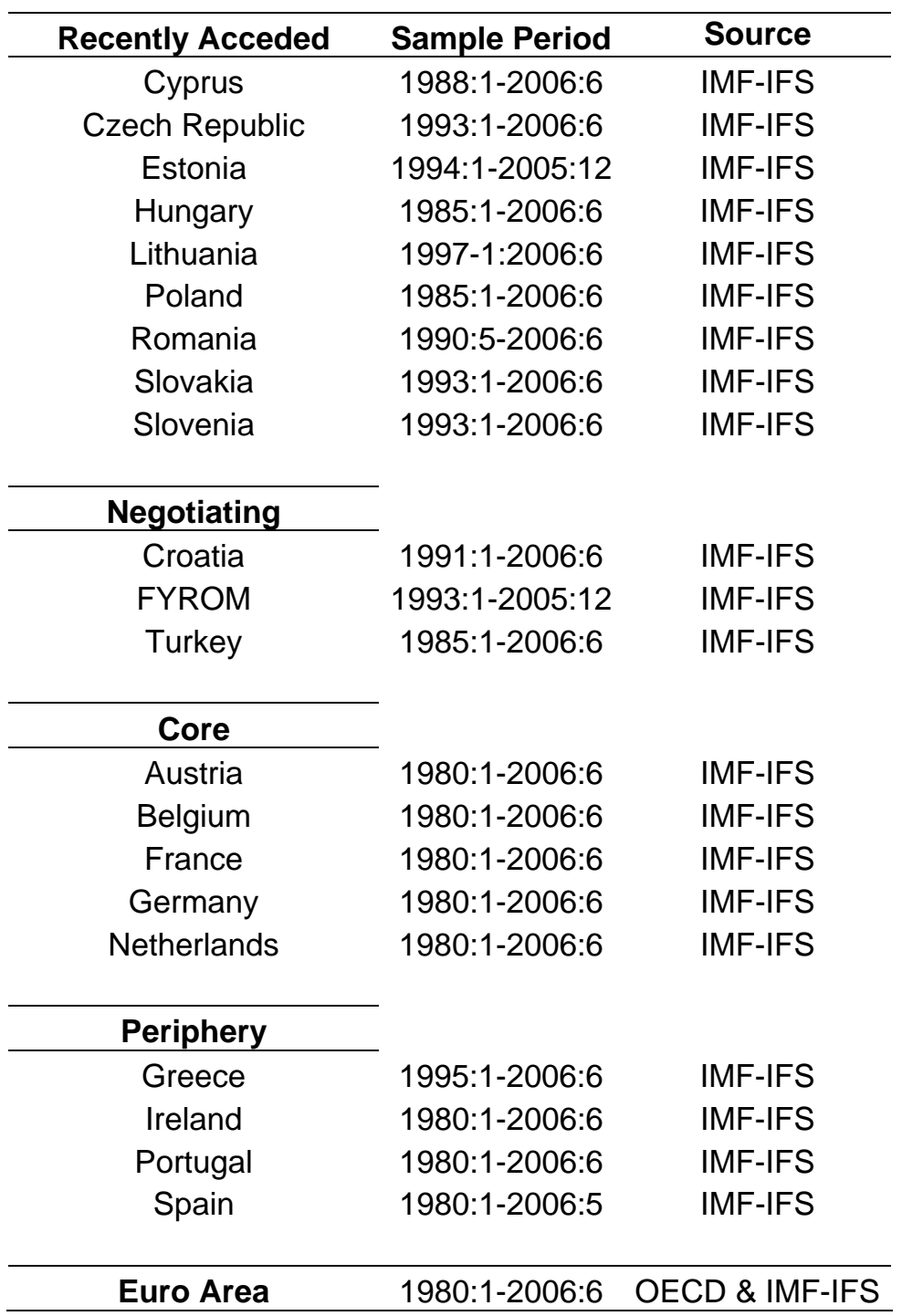


Figure 1: Time Profile of Business Cycles
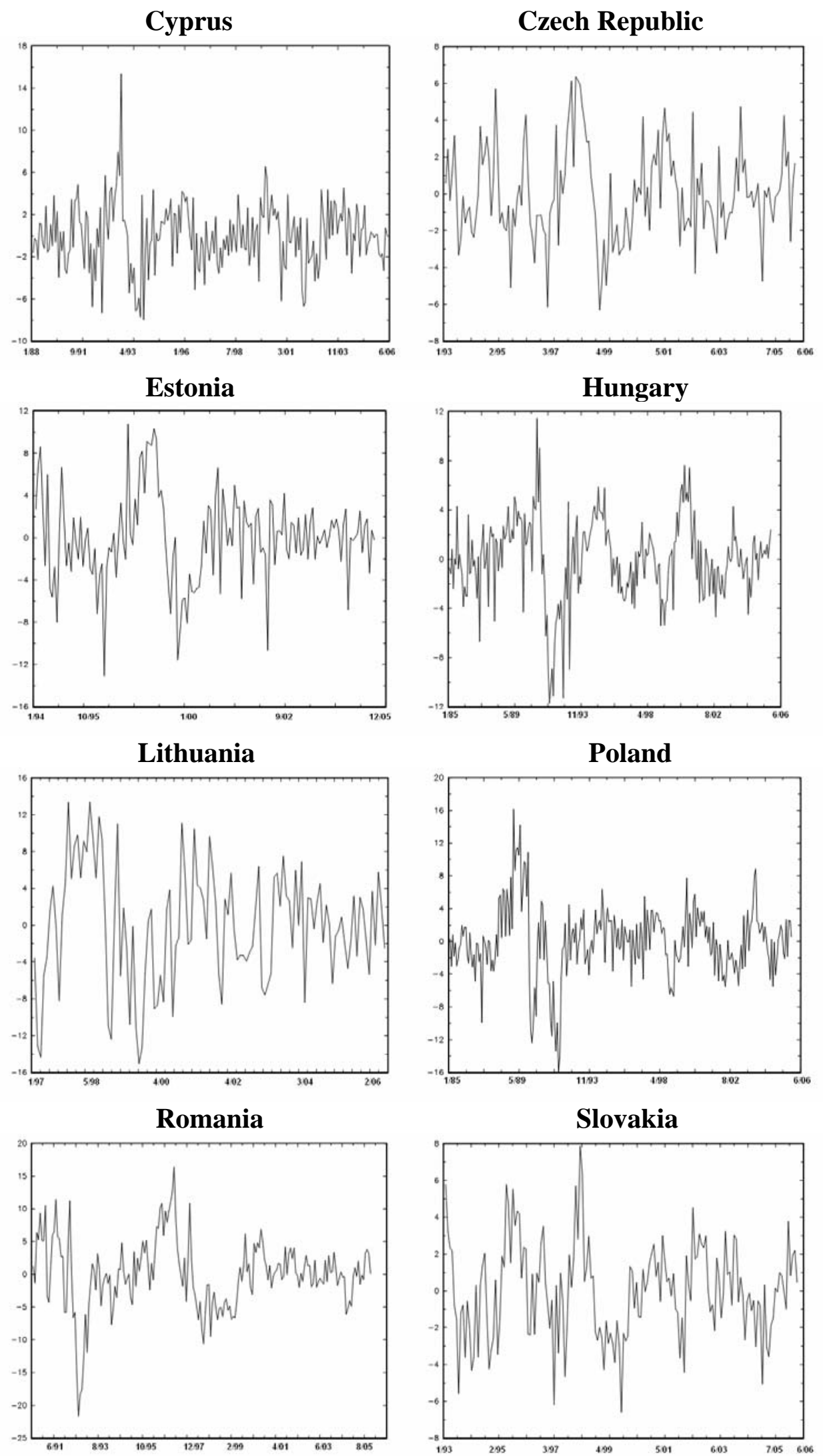
Figure 1 (Continues)

Slovenia



FYROM

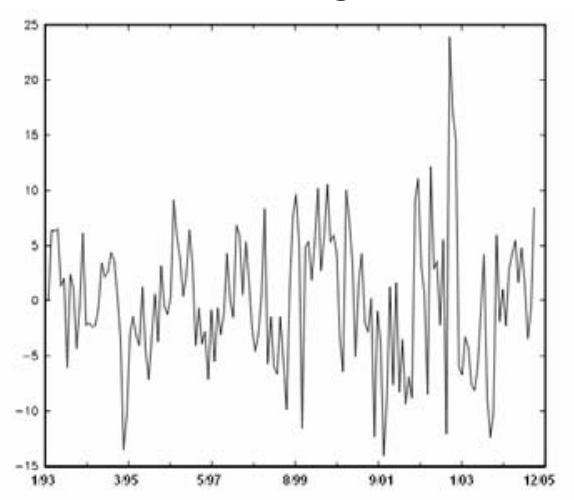

Croatia

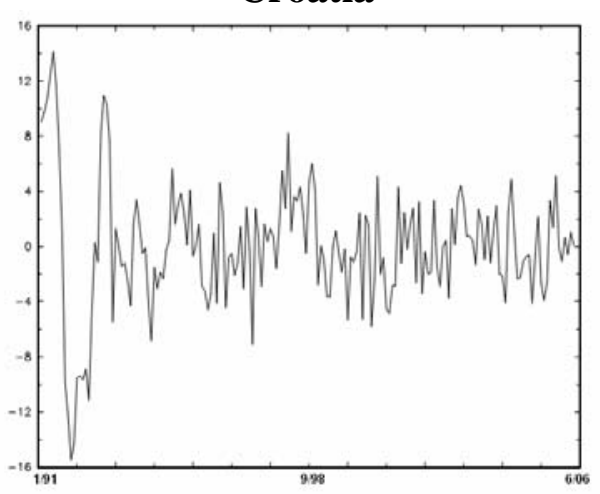

Turkey

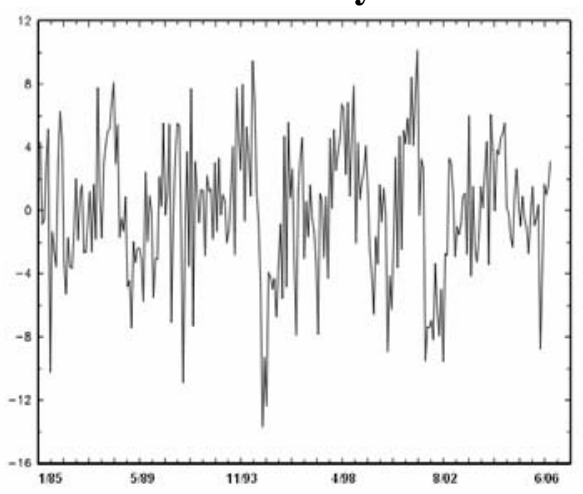

Euro Area

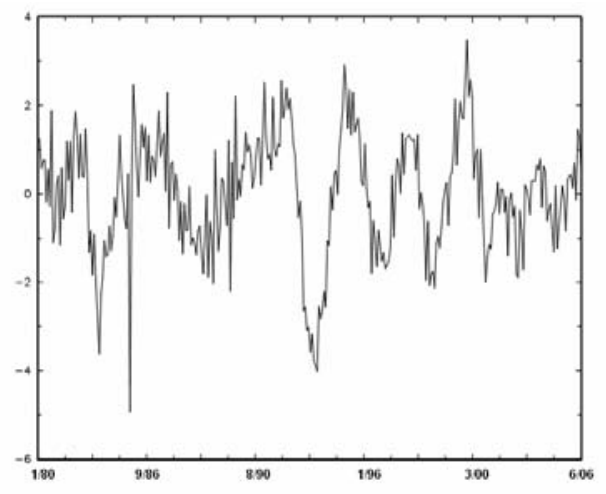


Figure 2: Transition of Business Cycle Correlations

Cyprus

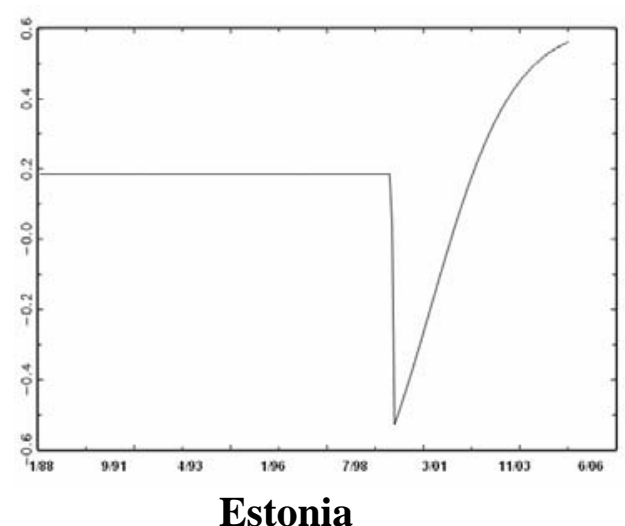

Estonia

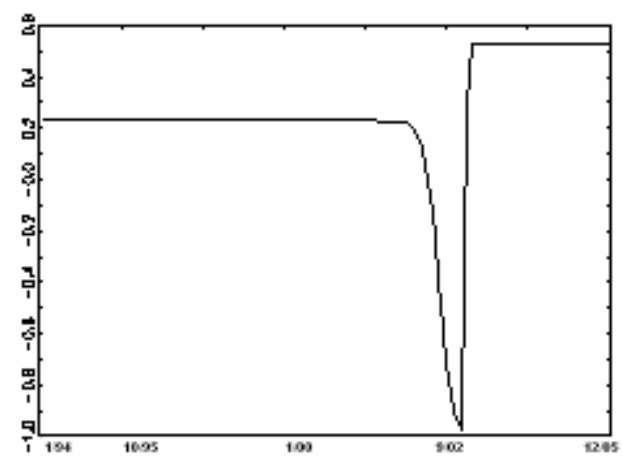

Lithuania

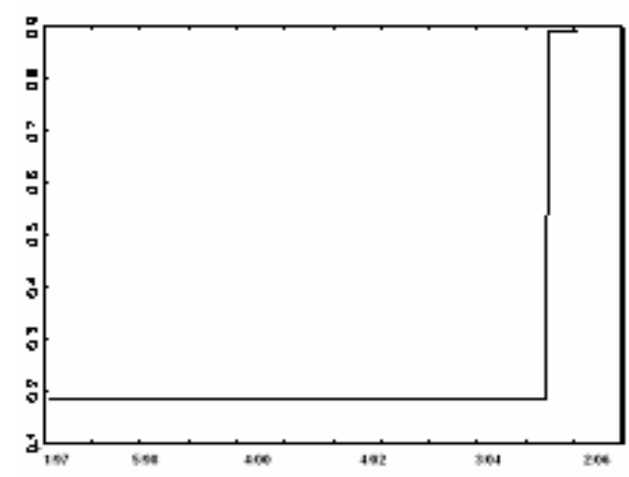

Romania

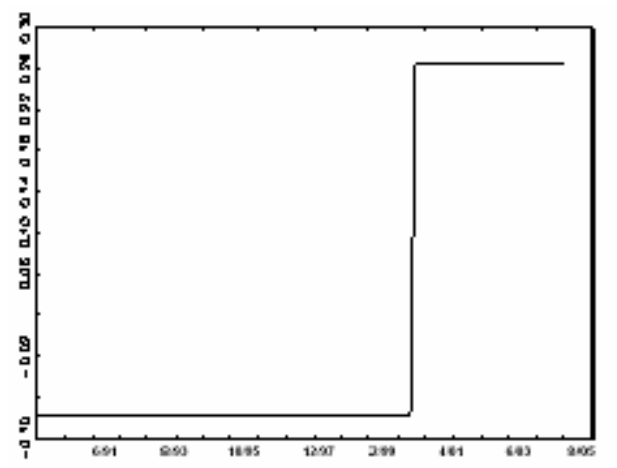

Czech Republic

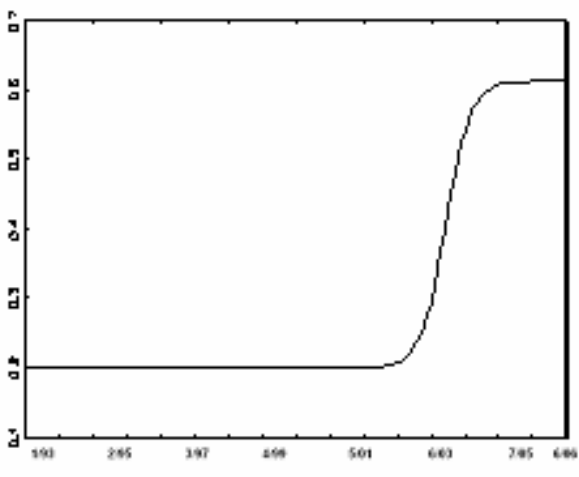

Hungary

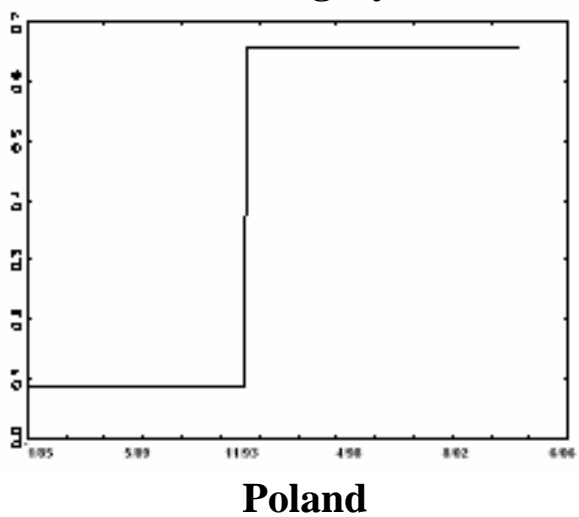

Slovakia

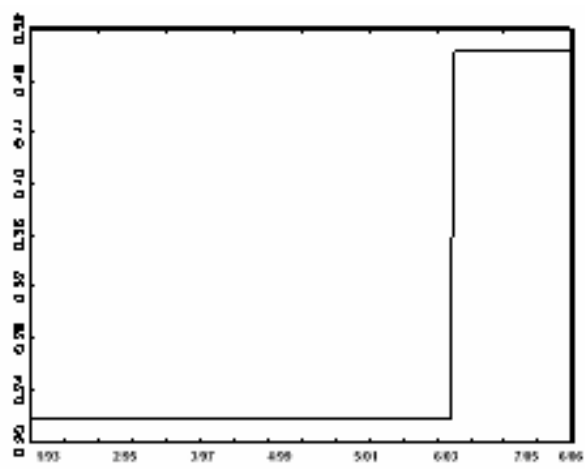


Figure 2 (Continues)
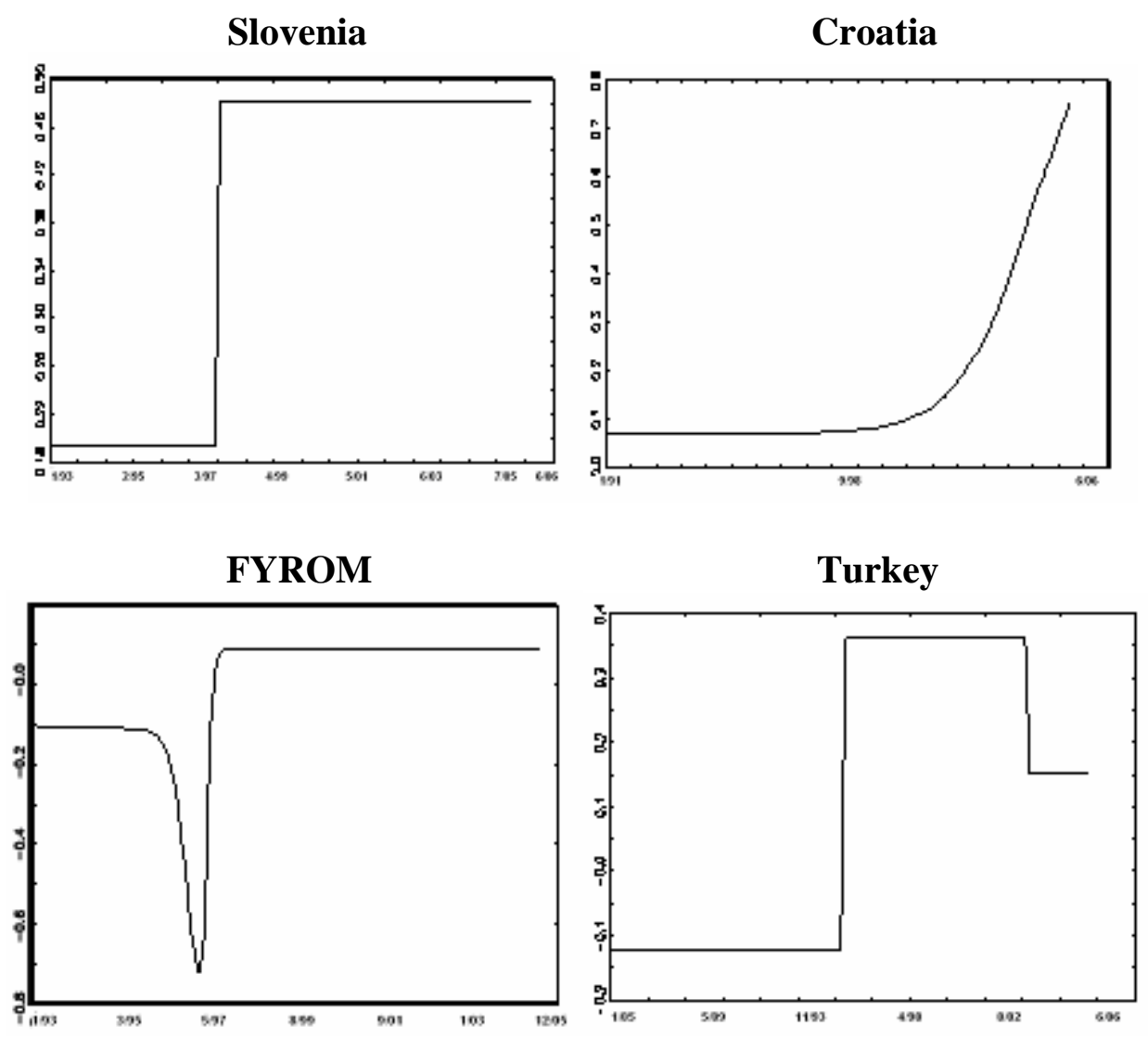